Kong. Res. J. 1(1) : 78-83, 2014

Kongunadu Arts and Science College, Coimbatore

\title{
PURIFICATION OF TOXIC DETERMINANT LECITHINASE FROM XENORHABDUS SP. AND THEIR LARVICIDAL POTENTIAL
}

\author{
Pavithra Sheetal, B*. and B. Lakshman Kumar \\ Department of Biotechnology, Kongunadu Arts and Science College, Coimbatore- 641029 \\ *E.mail: pavithrasheetal2gmail.com
}

\begin{abstract}
A symbiotic bacteria Xenorhabdus sp. was isolated from Entomopathogenic nematode Steinernema sp. using Insect bait method. This resulted in primary and secondary colony production. The primary colonies were selected for the lecithinase assay. Xenorhabdus produce various Exoenzymes in which the present study was concentrated on the exoenzyme Lecithinase which is the toxic determinant. Lecithinase activity of the bacteria was confirmed by lecithinase assay by spot inoculation of bacterial isolates on the nutrient broth supplemented with egg yolk emulsion, the opalescent zones were observed around the colonies producing the lecithinase enzyme after $24 \mathrm{hrs}$ and lecithovitellin reaction was also performed by inoculating the bacterial isolates into the egg yolk broth which resulted in the formation of opalescent suspension and flocculation of particles floating in the media. Lecithinase enzyme was partially purified using Sephadex G200 column chromatography. Protein profiling of partially purified lecithinase enzyme showed a single band at $70 \mathrm{kDa}$. Larvicidal activity of lecithinase was tested on Coleopteran white grub (Phyllophaga sp).It was found that with increasing concentrations of lecithinase, there was increase in mortality of the pest and vector. Thus this study confirms that the toxic determinant lecithinase can be used as potent larvicides for the control of insect pests of plants. The development of new strategies including naturally occurring larvicides to control white grub (Phyllophaga sp.) and it is important as the chemical larvicides may harm other soil dwelling organisms as well as humans.
\end{abstract}

Key word: Xenorhabdus sp., Lecithinase, larvicidal potential.

\section{INTRODUCTION}

Nematodes are round worms which are free living or parasites. Many of the parasite species cause diseases in plants, animals and others are beneficial in attacking insect pests are Entomopathogenic nematodes.Entomopathogenic nematodes (EPNs) in the families Steinernematidae and Heterorhabditidae represented by the genera Steinernema and Heterorhabditis respectively are lethal to insect parasites. They are symbiotically associated with mutualistic bacteria of genus Xenorhabdus for Steinernematidae and Photorhabdus for Heterorhabditis (Akhrust, 1993). Thus, it is nematode/bacteria complex that works together in biological control of several important insect pests (Kaya and Gaugler, 1993, Grewal and Georgis, 1998) and are important biotic factors in suppression of insect pest populations in soil. The virulent species of these nematodes are commercially produced as biological control agents all over the world encompassing North America, Europe, Asia and Australia in glasshouse crops, orchards, ornamentals, turf, lawn, and forestry. India has a great potential to exploit these beneficial nematodes to suppress the pest species.

The infective juvenile (IJ's) of EPN is a microscopic organism having 0.5 to $1.5 \mathrm{~mm}$ long depending on species. The third stage juvenile of these nematodes have closed mouth and anus and cannot feed until it finds an insect. It enters through the natural body openings (mouth, anus, spiracles) or thin cuticle and penetrates into the hemolymph using mechanical and enzymatic means (Abu hatab et al., 1995) and release bacteria.

Xenorhabdus sp. are gram negative, motile, rod shaped, faculatively anaerobic entomopathogenic bacteria belonging to family Enterobacteriaceae which are symbiotically associated with the infective stages of Entomopathogenic nematode Steinernema sp belonging to the families Steinernematidae. This bacteria nematode association is highly toxic to many insects and pests species and in most cases bacteria alone is more virulent once they are circulated with hemolymph of the pest (Forst and Nealson, 1996).

Xenorhabdus sp. secretes an array of exoenzymes that stimulate macro molecular degradation; the products together with bacteria themselves provide a nutrient for nematode growth and reproduction. When nematode population increases, nutrients become limiting in the insect cadaver, hence the nematode progeny re-associate with bacteria and differentiate into colonized, non- 
feeding IJs (Infective Juveniles) that emerge into the soil to forage for new hosts.

Lecithinase or phospholipases are one of the extracellular enzymes released by bacteria that have the ability to destroy animal tissues by destroying lecithin (phosphatidylcholine) in cell membranes. Bacterial lecithinase hydrolyses this lecithin which is charged so that it is soluble in water, whereas the compound formed by the hydrolysis is diglycerides which is not charged and insoluble in water.

\section{MATERIALS AND METHODS}

\subsection{Isolation of Symbiotic bacteria Xenorhabdus sp. from entomopathogenic nematode}

The Symbiotic bacteria Xenorhabdus sp. were isolated from the haemolymph of the entomopathogenic nematode infected larvae Rice moth (Corcyra cephalonica). Nematode infected cadaver were collected from the Insect Baiting trap and were surface sterilized. The larvae were cut open for the collection of haemolymph. This collected haemolymph were streaked on the freshly prepared NBTA media (NA + $0.0025 \%$ bromophenol blue $+0.004 \%$ triphenyltetrazolium chloride) (Akhurst, 1980). Primary colonies and secondary colonies were identified based upon the uptake of bromophenol blue from the NBTA media. Primary forms of the bacteria were maintained each week by streaking on to the fresh media and used for further studies. Morphological and biochemical identification of bacteria was performed.

\subsection{Lecithinase activity of bacteria Xenorhabdus $\mathrm{sp}$.}

The ability of bacteria to produce the lecithinase enzyme was determined by this method. A loop full of $24 \mathrm{hrs}$ grown culture was taken and spot inoculated on nutrient media supplemented with egg yolk emulsion $10 \mathrm{ml}$ egg yolk in $15 \mathrm{ml}$ sterile distilled water). The plates were incubated at $28^{\circ} \mathrm{C}$ for $24 \mathrm{hrs}$. Degradation of lecithin present in the egg yolk resulted in the formation of opaque precipitation around the colony. Lecithinase activity as also determined by Lecithovetlin reaction by inoculating the bacterial isolates in nutrient broth supplemented with egg yolk emulsion and incubated at $28^{\circ} \mathrm{C}$ for $48 \mathrm{hrs}$.

\subsection{Bacterial Lecithinase preparation}

Pure primary colonies of Xenorhabdus sp. were harvested and inoculated in $250 \mathrm{ml}$ conical flask containing $50 \mathrm{ml}$ of nutrient broth and incubated in a shaker incubator at $25^{\circ} \mathrm{C}$ for 6 days. Cell free supernatant was collected by centrifugation at $10000 \mathrm{rpm}$ for $30 \mathrm{~min}$ at $4^{\circ} \mathrm{C}$. Proteins present in the cell free supernatant were precipitated by $12 \%$ trichloroacetic acid. The precipitated proteins were dialysed over night at $4^{\circ} \mathrm{C}$ against $1 \mathrm{mM}$ Tris $\mathrm{HCl}$ buffer and the dialysed samples were used for partial purification by Sephadex G-200. The active fractions were pooled together and used for the determination of enzyme properties like $\mathrm{pH}$, temperature, stability and molecular weight determination of concentration of purified protein sample was determined by Lowry's method.

Agar diffusion assay (Giskow et al., 1988) was performed with $1 \%$ agar gel containing $0.01 \%$ lecithin, $0.1 \mathrm{M} \mathrm{NaCl}$ and 0.02 Tris ( $\mathrm{pH} 9) .3 \mu \mathrm{l}$ of crude preparation were added to wells made in the gels and incubated for 24 hours, enzymatic activity was determined by measuring the radius (in millimeters) of the precipitation zone in each gel.

Protein profiling of lecithinase was done using SDS-PAGE. (Laemmli, 1970). Samples were purified using crude dialysis and the purified samples were loaded on to the gel.

\subsection{Larvicidal activity of Lecithinase against White Grub (Phyllophaga sp.)}

Third instar larvae of white grub (larva of June beetle) were collected from the field of Kodappamund, Ooty,White grub (Phyllophaga sp.) $100 \mathrm{~g}$ of fine sterilized soil was put into plastic bottles and the moisture content were adjusted to $10 \%$ by adding requistite amount of sterilized distilled water. 25 white grub were placed in each bottles. The larvae were then sprayed with $2 \mathrm{ml}$ of lecithinase (in $\mathrm{mg}$ ) by a hand sprayer. Each treatment was repeated thrice. All the bottles were sealed with parafilm and incubated at $25^{\circ} \mathrm{C}$ for 48 hrs. Water alone was sprayed as control. The bottles were examined daily for the mortality.The lethal concentration $\left(\mathrm{LC}_{50}\right)$ Lecithinase of were calculated using MS Excel 2007 package.

\section{RESULTS}

Xenorhabdus isolates were found to be Gram positive, rod shaped, had ability to uptake Bromophenol blue from NBTA media (Fig1 A) and neutral red dye from Mac Conkey media (Fig1 B) and biochemical characterization showed negative for Catalase, Oxidase, indole, urease, Lactose fermentation, Glycerol fermentation and showed positive for gelatin hydrolysis, Nitrogen reduction test, Maltose fermentation, Methyl red (Figure 1). 
Figure 1: Biochemical and Morphological Characterization of bacterial isolates of Xenorhabdus sp.

(+) Positive, (-) Negative, Xhd-Xenorhabdus isolates.

(a)

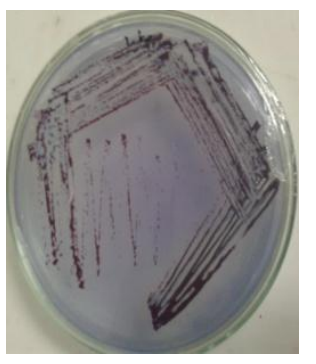

(b)

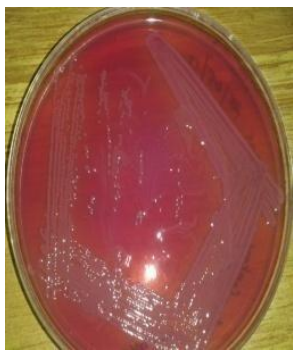

(a) Uptake of Bromophenol blue from NBTA media;

(b) Uptake of Neutral red dye from Mac Conkey media.

Lecithinase activity of bacteria were positive showing opalescent zone around the colonies producing the lecithinase enzyme whereas, in liquid broth showed opalescent suspension and flocculation of particles floating in the media as a curd. This confirms that the isolated symbiotic bacteria Xenorhabdus sp. produces the lecithinase enzyme. Lecithinase enzyme was extracted by inoculating the bacteria Xenorhabdus sp. in nutrient broth. Crude preparation of lecithinase enzyme was precipitated with $12 \%$ Trichloroacetic acid and purified using Sephadex G-200 Column Chromatography. Protein content for all the fractions were determined at $280 \mathrm{~nm}$ by UVSpectrophotometer. The peak fractions were assayed for observing the presence of lecithinase enzyme in the fractions (Fig 4).This fraction was used for checking the Larvicidal potential.

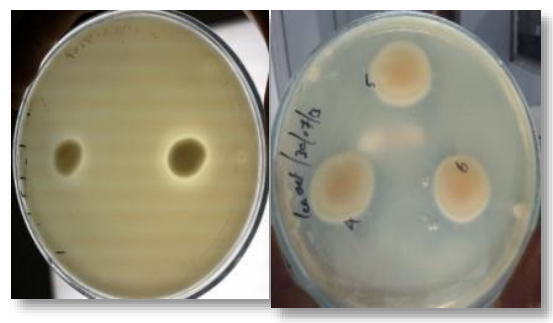

Lecithinase activity of Bacteria Xenorhabdus isolates on Nutrient media supplemented with egg yolk emulsion

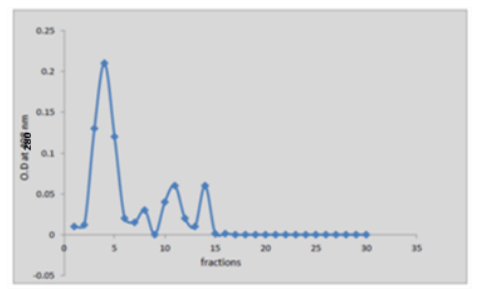

Column purification (Sephadex G-200) of lecithinase enzyme in Xenorhabdus sp.

\subsection{Characterization of lecithinase enzyme}

\subsubsection{Effect of Temperature on the activity of the enzyme Lecithinase}

The optimum temperature of the enzyme lecithinase, in various temperature ranging from $10^{\circ} \mathrm{C}-70^{\circ} \mathrm{C}$ The optimum temperature activity was noticed at $30^{\circ} \mathrm{C}$, after which the activity of the enzyme was found to decrease. (Fig 6).

\subsubsection{Effect of $p H$ on the activity of the enzyme Lecithinase}

The activity of the enzyme lecithinase in the presence of different $\mathrm{pH}$ ranging from 3.0 to 10 using the phosphate buffer was observed. The enzyme exhibited optimum activity at the pH 7.0. (Fig 7).

\subsection{Effect of Temperature on the Stability of the enzyme Lecithinase}

Lecithinase was treated at different temperatures ranging from $10^{\circ} \mathrm{C}-70^{\circ} \mathrm{C}$ and the stability of the enzyme was observed. The enzyme was found to be stable upon $40^{\circ} \mathrm{C}$ To $50{ }^{\circ} \mathrm{C}$ and therefore the enzyme activity was found decreasing below $40^{\circ} \mathrm{C}$ ( Fig 8).

\subsection{Larvicidal potential of the lecithinase against White grub (Phyllophaga sp.)}

Larvicidal potential of the toxic determinant lecithinase was performed against white grub (Phyllophaga sp.). Lethal Concentration $\left(\mathrm{LC}_{50}\right)$ of Lecithinase against White grub (Phyllophaga sp.) was found to be $8.6 \mathrm{mg}$. Linear regression analysis resulted in a value of 0.969 which was found to be significant at $\mathrm{p}<0.01$.

Fig 6 Effect of temperature on the activity of the lecithinase enzyme of Xenorhabdus sp.

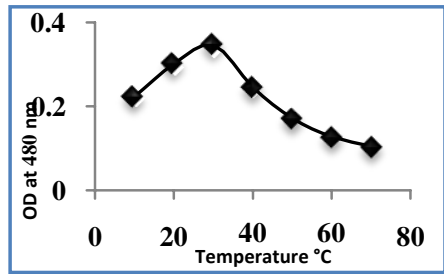

Fig 7: Effect of pH on the activity of the lecithinase enzyme of Xenorhabdus sp.

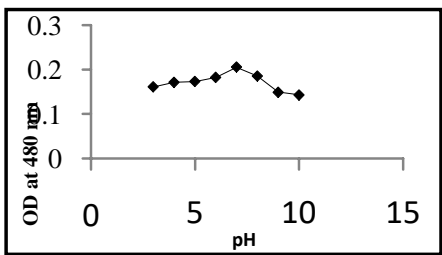


Fig-3 Effect of temperature on the stability of the lecithinase enzyme of Xenorhabdus sp.

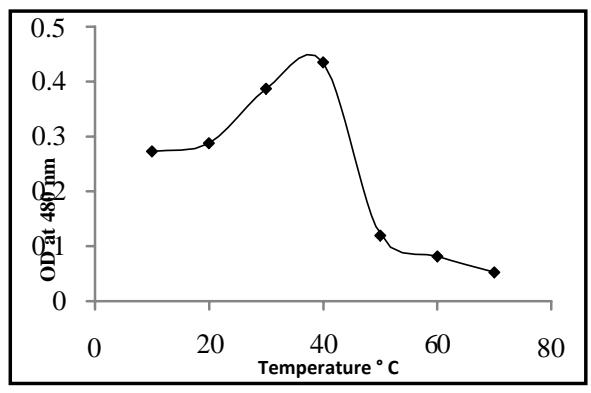

Lecithinase concentration and percentage of Mortality

\begin{tabular}{|c|c|c|c|c|}
\hline S.No & $\begin{array}{l}\text { Bacterial } \\
\text { colonies }\end{array}$ & $\begin{array}{l}\text { CFU* }^{*} \text { 10 }^{-} \\
7 / / \mathrm{ml}\end{array}$ & $\begin{array}{l}\text { Mean } \\
\text { of dead } \\
\text { larvae }\end{array}$ & $\begin{array}{l}\text { \% of } \\
\text { Mortality }\end{array}$ \\
\hline 1. & 154 & 1.5 & 1 & 4 \\
\hline 2. & 175 & 1.7 & 2 & 8 \\
\hline 3. & 282 & 2.8 & 6.6 & 26.4 \\
\hline 4. & 362 & 3.6 & 12.6 & 50.4 \\
\hline 5. & 456 & 4.5 & 25 & 100 \\
\hline
\end{tabular}

Lecithinase $\mathrm{LC}_{50}$ determination for White Grub (Phyllophaga sp.)

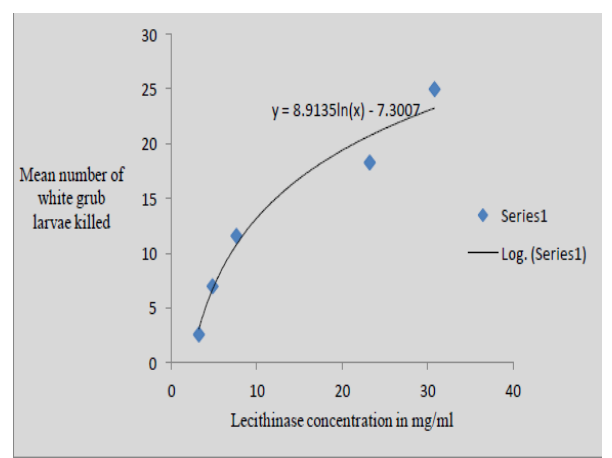

\section{DISCUSSION}

Xenorhabdus sp is a gram-negative bacterium belonging to family Enterobacteriaceae. The bacteria reside as endosymbionts in the foreguts of soil nematodes belonging to the genus Steinernema. Bacteria are released from the gut upon invasion of the insect hemocoel by the nematode. Bacterial multiplication and secretion of toxic proteins are the primary causes of death of the insect host. The bacteria alone are known to be sufficient to cause larval mortality following injection into the hemocoel or following oral administration when they are mixed in the diet. (Khandelwal and Bhatnagar, 2003)

In the present study, the hemolymph of the insect Corcyra cephalonica larvae infected with five isolates of different Entomopathogenic nematodes were streaked on NBTA media for the isolation of the symbiotic bacteria Xenorhabdus sp.The infected rice moth (Corcyra cephalonica) were brown in colour obtained from five soil samples, which was in accordance with the finding of Woodring and kaya (1988).

The mutualistic mode of living of the entomopathogenic bacterium in the nematode gut turns into a pathogenic mode when the bacterium enters the larval hemocoel. X. nematophilus is known to secrete highly potent protein toxins into the hemocoel, which rapidly kill the larval host. The insect carcass provides a rich nutrient source on which both the bacteria and the nematode feed, grow, and replicate(Khandelwal and Bhatnagar, 2003).

In this study the cultures were found to be negative for indole production, voges proskaures test, catalase, lactose fermentation and urease and showed positive results for maltose fermentation, glycerol fermentation, citrate utilization, nitrogen reduction test and gelatin hydrolysis test. These results were similar to the reports of Boemare and Akhrust (1998). Morphological characteristics of the symbiotic bacteria used for the present study showed that it was gram negative, rod shaped, motile and have ability to absorb bromophenol blue from NBTA media and neutral red dye from Mac Conkey media. These results were also observed by Boemare and Akhrust (1988) and Yamanaka et al. (1992). This confirmed that the bacteria was Xenorhabdus sp.

Xenorhabdus sp. selected for the present study showed lecithinase activity. Lecithinase activity of the Xenorhabdus isolates was observed by the formation of an opalescent suspension which raised to the top of the medium as a curd. This was based on Macfarlane and Knight (1941) method, who found that the change in the egg yolk broth is due to the hydrolysis of lecithin. The enzymatic hydrolysis of lecithin results in the loss of its emulsifying properties and causes the separation of fatty substances in the egg yolk media.

Xenorhabdus $s p$ are known to produce lecithinase along with other enzyme like protease, lipase which is involved in providing the nutrients for both the nematode and the bacteria. These bacteria release digestive enzymes into the haemolymph of the insect cadaver and breakdown the macromolecules of the insect cadaver to provide nutrient supply (Frost and Nealson, 1996). It has been speculated that it contributes to the 
inactivation of the insect immune system (Issacson and Webster, 2002).

In the present study, the Lecithinase activity for the crude and the purified fraction by sephadex columns was observed by agar diffusion method. Crude and the 4th fraction (Sepdadex G- 200) showed the precipitation zone around the wells in Agar diffusion method.

Giskow et al. (1988) and Thaler et al. (1998) found that the lecithinase purified from Xenorhabdus nematophilla only in 6th and 8th fractions using HPLC showed the total activity of lecithinase in agar diffusion method. Thaler et al. (1998) found that only the phase I variants of Xenorhabdus nematophilus and Xenorhabdus bovienii strains produced lecithinase activity when the bacteria were grown on a solid lecithin medium. Singh et al. (1999) observed that the lecithinase activity in $K$. pneumoniae produced lecithinase positive colonies on egg yolk agar. Hence in the present study it was confirmed that the bacteria Xenorhabdus sp from primary colonies produced lecithinase enzyme.

The partially column purified enzyme was subjected to optimization studies. In present study, the maximum activity of the enzyme was found at $30^{\circ} \mathrm{C}$ and $\mathrm{pH} 7.0$ and was stable at the temperature $40^{\circ} \mathrm{C}$.Change in $\mathrm{pH}$ and the temperature effects the enzyme activity. $\mathrm{pH}$ and temperature may change the properties of the substrate so that it cannot bind to the active sate or it cannot undergo catalysis. So enzyme typically have an optimum activity with respect to $\mathrm{pH}$ and temperature conditions.

In the present study, a single band was seen on the SDS-PAGE from purified fraction using Sephadex G -200 column indicating the lecithinase in the culture supernatant of Xenorhabdus sp. had a molecular mass approximately 70KDa. This was also confirmed by zymogram assay which showed a single very faint and thin precipitated band.

Singh et al. (1999) noted that Lecithinase activity in Klebsiella was a rare trait as out of 208 strains of Klebsiella belonging to 3 species only 4 strains of $\mathrm{K}$. pneumoniae produced lecithinase positive colonies on egg-yolk-agar. Purified lecithinase was determined to be a high molecular weight (70 kDa), crystalizable, anionic (pI, 3.5) protein. It possessed cytolytic, hemolytic and dermonecrotic activities but did not induce fluid accumulation in rabbit ileal loop or infant mouse guts.

An important alternative measure to chemical insecticides is biological control measure which involves the regulation of pest population using natural control agents such as predators, nematodes and microbial insecticides. It is the use of one biological organism to control another, releasing beneficial bacteria, fungi or arthropods to limit pest infestation .

The Xenorhabdus lecithinase may participate in the virulence of the nematobacterial complex by allowing intracellular bacterial growth in insects in the same way that phospholipase $C$ acts in B. thuringiensis virulence (Bucher, 1960). Many of these lecithinases have been purified and characterized as single secreted-polypeptide proteins. Lecithinases are toxic determinants, as well as a means of securing bacterial supplies of phosphates. They may also have an important role in the induction of pathogenicity in host organisms (Thaler et al., 1998).

\section{CONCLUSION}

This study thus proves the bioactive potential purified enzymes like lecithinase from the entomopathogenic and symbiotic bacteria Xenorhabdus sp have Larvicidal activity against the white grub (Phyllophaga sp.). It also offers scope for discovery of many more such products from the bacteria associated nematodes which could be used to control insect pests.

\section{REFERENCES}

Abu Hatab, M., S. Selvan and R. Gaugler, (1995). Role of protease in the penetration of insect gut by the Entomopathogenic nematode, Steinernema glaseri (nematode:Steinernematidae). J. Invertebr.Pathol. 66:125-130. 9

Ahkrust, R. J and G. Dunphy, (1993). Tripartite interactions between symbiontically associated entomopathogenic bacteria, nematode and their insect hosts. Parasites and pathogens of insects. 2: 1-23.

Akhurst, R.J., (1980). Morphological and Functional Dimorphism in Xenorhabdus spp., Bacteria Symbiotically Associated with the Insect Pathogenic Nematodes Neoaplectana and Heterorhabditis. J. Gen. Microbiol. 121, 303-309.

Boemare, N. and R. J. Akhurst, 1988. Biochemical and physiological characterization of colony form variants in Xenorhabdus spp. (Enterobacteriaceae). J. Gen. Microbiol. 134:751-761.

Boemare, N., R.J. Akhrust and R. G. Mourant, (1993). DNA relatedness between Xenorhabdus spp. (Enterobacteriaceae), symbiotic bacteria of Entomopathogenic nematodes and a proposal 
to transfer Xenorhabdus luminescens to a new genus, Photorhabdus gen nov. Int. J. Syst. Bacteriol. 43:249-255.

Castelli, M.E., G.V. Fedrigo, A.L. Clementin, M.V. Ielmini, M.F. Feldman and E.G. Vescovi, (2008). Enterobacterial Common Antigen Integrity Is a Checkpoint for Flagellar Biogenesis in Serratia marcescens. J. Bacteriol, 190:213.

Forst, S. and K. Nealson, (1996). Molecular Biology of the Symbiotic-Pathogenic Bacteria Xenorhabdus spp. and Photorhabdus spp. Microbiol. Rev. 60: 21-43.

Gaugler, R. and H.K. Kaya,( 1990). Soil type and Entomopathogenic nematode persistence. J. Invertebr. Pathol. 55: 401-406.

Giskow, M, L. Olsen and S. Molin, (1988). Cloning and expression in Escherichia coli of the gene for extracellular phospholipase A1 from Serratia liquefaciens. J. Bacteriol. 170:5855-5862.

Grewal, P.S, and R. Georgis, (1998). Entomopathogenic nematodes. In :Hall FR and Menn J. eds. Methods in Biotechnology, Vol.5: Biopesticides : Use and delivery. Humana Press. Totowa, NJ. pp.271-299.

Issacson, P.J and J.M. Webster, (2002). Antimicrobial activity of Xenorhabdus sp. RIO (Enterobacteriaceae) symbiont of the entomopathogenic nematode, Steinernema riobrave (Rhabditida: Steinernematidae). J. Invertebr. Pathol.79, 146-153
Khandelwal, P. and N.B. Bhatnagar, (2003). Insecticidal Activity Associated with the Outer Membrane Vesicles of Xenorhabdus Nematophilus, Appl. Environ. Microbiol. 69:2032.

Laemmli, U.K., (1970). Cleavage of structural proteins during the assembly of the bacteriophage T4. Nature. 277:621-626.

Macfarlane, M.G. and B.C. Knight (1941). The biochemistry of bacterial toxins. I.The lecithinase activity of Clostridium welchii toxins. Biochem.J. 35:884-902.

Singh, B.R., V.D. Sharma and R. Chandra (1999). Detection, prevalence, purification and characterization of lecithinase of Klebsiella pneumoniae. Indian J Exp Biol. 37(9):925-32

Thaler, J.O, B. Duvic, A. Givaudan, N.E. Boemare, (1998). Isolation and Entomotoxic Properties of the Xenorhabdus nematophilus F1 Lecithinase. Appl. Environ. Microbiol. pp: 2367-2373

Yamanaka, S., A. Hagiwara, Y. Nishimura, H. Tanabe and Ishibashi, (1992). Biochemical and physiological characteristics of Xenorhabdus species symbiotically associated with entomopahtogenic nematodes including Steinernema kushidai, and their Pathogenecity against Spodoptera litura (Lepidoptera: Noctuidae). Arch. Microbiol. 158:387-393. 